\title{
USE OF RADIOCARBON DATING IN ASSESSING CHRISTIAN CONNECTIONS TO THE DEAD SEA SCROLLS
}

\author{
G A Rodley \\ RD2 Picton, New Zealand \\ B E Thiering \\ c/o School of Studies in Religion, University of Sydney, 2006 Australia
}

ABSTRACT. We present an analysis of radiocarbon dates on Dead Sea Scrolls that have a bearing on the question of the Scroll documents' relation to Christian origins. We assess details of dating reports, discuss paleographical evidence, and consider the content of the documents. When collated, these findings may be seen as compatible with a view that personalities mentioned in the Scrolls were contemporary with the founders of Christianity.

\section{INTRODUCTION}

Radiocarbon dating provides important information about the dates of some of the Dead Sea Scrolls, a matter of interest to the claim that they are closely connected with earliest Christianity.

The manuscripts properly called Dead Sea Scrolls were found at Qumran, near the northwest corner of the Dead Sea. Other, related documents that have been ${ }^{14} \mathrm{C}$ dated were found at nearby locations in the Judean Desert. All historical indications point to their production in the general period of Jewish history extending from the third century BCE to the second century CE.

${ }^{14} \mathrm{C}$ tests make it possible to give, within a statistically probable range, a date of manufacture of the writing material, either parchment (made from animal skin) or papyrus. This is not necessarily the same as the date of composition of the works inscribed on them. Some of the Dead Sea Scrolls, for example, were copies of the Old Testament, composed long before. Nor is the date of manufacture of the material necessarily exactly the same as the date when it was written on; manufacture may have preceded scribal use by a longer or shorter period of time. But in exceptional circumstances, an example of which will be given below, the date of manufacture can provide the dates of both composition and recording of the work.

The Dead Sea Scrolls that have aroused most interest are new works, not previously known, usually called the sectarian works. The contents of some of them give rise to the question whether the writers were in the immediate background of earliest Christianity, or were indeed part of that history themselves. Figures appear in these writings, always under pseudonyms, one called the Teacher of Righteousness, another referred to as the Wicked Priest. The dates when they lived, within the broad period of the Scrolls' production, are uncertain, and their identities have only been conjectured. The date of the writing material on which works discussing them are inscribed is, therefore, relevant to the question of their historical date, although not by itself conclusive.

Two ${ }^{14} \mathrm{C}$ dating studies have been made, one by Bonani et al. $(1991,1992)$ and another by Jull et al. $(1995,1996)$. The Bonani et al. (Zurich) study included only 2 documents of direct relevance to the argument for a Christian connection, but because the whole study provided a good match between ${ }^{14} \mathrm{C}$ values and paleographical assessments, this led to the view that the placement of the Teacher in the BCE period had been confirmed based on paleographical grounds. In the case of the Jull et al. Tucson study, comments made in the reports make it clear that the study aimed to determine whether the Scrolls have Christian connections, and it included 7 documents of direct relevance.

The results of both studies have been examined by G Doudna of Copenhagen (Doudna 1998); the present study considers some of the questions he has raised. 
${ }^{14} \mathrm{C}$ DATING OF SCROLL SAMPLES

\section{Extension of Results, Using Stuiver (1998) Calibration}

Dating of the Scrolls is complicated by the existence of ${ }^{14} \mathrm{C}$ values, especially around $1900-2100$ $\mathrm{BP}$, that can correspond to more than one cal BCE/CE range. As a consequence, Scroll dates overall have somewhat wider $1 \sigma$ calibrated age ranges than might otherwise be expected for the level of accuracy obtained by the ${ }^{14} \mathrm{C}$ measurements.

All calibrated ages presented from the Tucson and Zurich studies were derived using the bidecadal Stuiver and Pearson (1986) calibration curve, except for an invocation of the decadal Stuiver and Becker (1986) curve in one instance by Jull et al. (1995). In Table 1 we use ranges derived from the Stuiver et al. (1998) curve (as reported by Doudna 1998) for the two Zurich and the seven Tucson documents of relevance, since these show some important differences from the Stuiver and Pearson (1986) ones. In some instances these contain separate subranges, due to the variations mentioned above. But these are of secondary significance for the dating considered here.

The most significant change is to the more recent extreme of the $1 \sigma$ range for a key document, $1 \mathrm{QpHab}$. The relevance of this change is considered in more detail below.

Table 1 Stuiver et al. (1998) $1 \sigma$ calibrated age ranges (from Doudna 1998, Table A) with originally reported (Stuiver and Pearson 1986) $1 \sigma$ values given in brackets

\begin{tabular}{lll}
\hline Scroll & \multicolumn{2}{c}{ Calibrated age range } \\
\hline Zurich laboratory & & \\
$11 \mathrm{QT}^{\mathrm{a}}$ (Temple Scroll) & $53 \mathrm{BCE}-21 \mathrm{CE}$ & {$[97 \mathrm{BCE}-1 \mathrm{CE}]$} \\
1QH (Thanksgiving & $37 \mathrm{BCE}-68 \mathrm{CE}$ & {$[21 \mathrm{BCE}-61 \mathrm{CE}]$} \\
$\quad$ & & \\
Scroll) & & {$[5-80 \mathrm{CE}]$} \\
Tucson laboratory & $4-82 \mathrm{CE}$ & {$[104-43 \mathrm{BCE}]$} \\
4Q266 & $88-2 \mathrm{BCE}$ & {$[159 \mathrm{BCE}-20 \mathrm{CE}]$} \\
1QpHab & $164-144 \mathrm{BCE} ; 116 \mathrm{BCE}-50 \mathrm{CE}$ & {$[11 \mathrm{BCE}-78 \mathrm{CE}]$} \\
1QS & $36 \mathrm{BCE}-81 \mathrm{CE}$ & {$[22-78 \mathrm{CE}]$} \\
4Q258(second sample) & 29-81 CE & {$[35 \mathrm{BCE}-59 \mathrm{CE}]$} \\
4Q171 (4QpPs $\left.{ }^{\mathrm{a}}\right)$ & $39 \mathrm{BCE}-66 \mathrm{CE}$ & {$[172-98 \mathrm{BCE}]$} \\
4Q521 & $168-51 \mathrm{BCE}$ & \\
4Q267 & &
\end{tabular}

\section{Features of the Dead Sea Scrolls Dating Studies}

Considerable care is required in the preparation of Scroll samples for radiocarbon analysis because of various historical storage conditions and chemical treatments of these documents (Caldararo 1995). Both groups who have made measurements addressed these problems carefully. Bonani et al. specifically checked the effect of gelatinization on three documents (two of which are ones cited here, $11 \mathrm{QT}^{\mathrm{a}}$ and $\left.1 \mathrm{QH}\right)$. They concluded that gelatinization does not affect the ${ }^{14} \mathrm{C}$ age.

The Tucson laboratory distinguished two categories of parchment sample, "Type 1", which appeared to be relatively clean, and "Type 2", contaminated with perspex glue. Reanalysis of one of the latter, 4Q258, suggested that an earlier measurement may have involved insufficient pretreatment of the sample. Of the seven Scroll samples studied by Jull et al. that are relevant to the question of Christian connections, only 4Q266 (in addition to 4Q258) fell into the Type 2 category; the others 
cited here were Type 1 . The possibility of contamination by castor oil, used to highlight letters by the first generation of Scroll scholars, has also been raised; we consider this question below.

A feature of the Zurich study was an apparent displacement of basic cal BCE/CE values toward older ages than expected from known dates and those estimated from paleographical studies, as noted by Bonani et al. (1992) and analyzed by Rodley (1993). However, as pointed out to us by Doudna (personal communication 1998; unreferenced), if the more recent calibrations are applied to the Zurich results, key features of the displacement disappear.

The Tucson study is linked to the Zurich one through their common measurement of one document, 1 QIsa. The value determined by Tucson is in good agreement with Zurich. Consequently, we use Stuiver et al. (1998) derived ranges for the two Zurich documents related to the case presented here, the Temple Scroll and the Thanksgiving Scroll (Table 1).

\section{${ }^{14} \mathrm{C}$ Dating of Date-Bearing Papyrus Documents}

In both the Zurich and Tucson studies, measurements were also made of certain documents as a check of the carbon-dating procedure. These documents bore an actual date, because they had the status of legal records. All of them were papyri. The cal BCE/CE values of Bonani et al. gave good agreement with the known dates, while the cal BCE/CE values of Jull et al. in all three cases showed a younger-age displacement from the known dates (Jull et al. 1995, Figure 1). In the case of one date-bearing sample, from Kefar Bebayou, the known date of writing, $135 \mathrm{CE}$, is well before the $1 \sigma$ Stuiver et al. (1998) range of 237-340 CE and even before the broader $2 \sigma$ range of $140-390 \mathrm{CE}$.

Obviously, the papyrus was not cut after the date of recording, so some other common factor appears to have affected these measurements. Jull et al (1995, p 16) commented that the explanation might be that at the point involved (close to $130 \mathrm{CE}$ ) the calibration curve needed to be "slightly lowered". But the Zurich set of specific-age samples included two in just this age region, and the good agreement found for those would appear to eliminate the curve-adjustment possibility.

Instead, the displacement may indicate contamination, and a suggestion may be made about its source. (This would apply only to papyrus, made from reeds, not to the parchment, made from animal skin, on which the scrolls relevant to the Christian history were written.) The Tucson papyri ${ }^{14} \mathrm{C}$ values may reflect insufficient acid pretreatment to eliminate all inorganic carbonate. The papyrus used would have grown in areas containing significant calcium carbonate (crystallization of the aragonite form is a notable feature of the region). Thus, it is possible that the papyrus writing material may have contained small crystals of aragonite. Such crystalline material would have contained ${ }^{14} \mathrm{C}$ that was contemporary with the time of papyrus growth, in which case residual inorganic carbonate would not have affected the measurements. But the possibility exists that, over the historical existence of the papyri samples, more recent ${ }^{14} \mathrm{C}$ became incorporated into the aragonite. That could occur via dynamic equilibrium of the aragonite carbonate with atmospheric carbon dioxide, facilitated by the presence of moisture. Contemporary exposure to moisture could have enhanced such a process, thereby adding a significant amount of very recent ${ }^{14} \mathrm{C}$. If acid treatment had not been sufficient to remove all carbonate-and this becomes more likely for any embedded crystalline material-some "additional" inorganic ${ }^{14} \mathrm{C}$ may have remained.

Acid treatment in the case of the Tucson study was carried out for a shorter time and at lower temperature than in the Zurich study. Although a somewhat higher acid concentration was used by Jull et al., the kinetic factors of time and temperature could have been the more significant ones with respect to complete removal of carbonate. Consequently, the residual presence of more recent inorganic ${ }^{14} \mathrm{C}$ may have contributed to the age displacement observed for the papyri samples. This pos- 
sibility could be tested by remeasuring new samples of the papyri documents using more extensive acid pretreatment.

As mentioned, carbonate in papyri samples would be embedded in the fibers as the result of formation during the growth of the papyrus. By contrast, Scroll parchments, made from animal skin, would be potentially subject only to surface effects capable of being readily removed by the cleaning/acid treatment.

\section{CONTENTS OF THE SCROLLS AND THEIR BEARING ON DATING}

Along with the date of manufacture of the writing material, the contents of the documents provide evidence of the date of composition and recording of the sectarian scrolls. After describing the general principles for using such evidence, we apply them to specific documents.

As in the case of the papyri, a document from this period may contain the actual date of its composition and recording. Let us suppose a hypothetical document $\mathrm{A}$, bearing a date equivalent in our terms to $1 \mathrm{March}, 50 \mathrm{CE}$. But the ${ }^{14} \mathrm{C}$ date for the preparation of its writing material (corresponding to the killing of the animal whose skin was used, or the cutting of the papyrus), turns out to be mid-first century BCE. It would then be certain that the scribe of this document used an old piece of writing material. This is always possible in a situation where writing materials were scarce and valuable. Actual evidence for the use of old pieces will be given below.

Or, if a document contained no date, it might still describe certain events whose date is known to us. For example, a hypothetical document $\mathrm{B}$ might describe in exact detail the fall of Jerusalem, which took place in $70 \mathrm{CE}$. If its writing material were ${ }^{14} \mathrm{C}$-dated to the previous century, it would again be the case that the scribe used an old piece of material.

In a different and exceptional set of circumstances, the ${ }^{14} \mathrm{C}$ dating could give positive information about the date of the events described, a date otherwise unknown. Let us suppose a hypothetical document $\mathrm{C}$, which describes the activities of a person $\mathrm{X}$ whose date is not known to us. That person is said to be still alive at the time of writing. He must therefore have been alive after the date of manufacture of the writing material. The only exception to this rule would be a case where document $\mathrm{C}$ is a copy of an earlier document. But if it is certain that document $\mathrm{C}$ was the original and not a copy, then we have discovered that person $\mathrm{X}$ lived after the ${ }^{14} \mathrm{C}$ date of document $\mathrm{C}$. The record of his activities could not have been made on material that did not yet exist.

\section{Key Documents for the Date of the Teacher}

It is important to distinguish documents naming or directly reflecting the presence of the Teacher of Righteousness from other Qumran documents. The scribal community was at work over a long period, and some of their productions were composed early in their history. But one distinctive group having common characteristics, with similar organizational features and doctrinal emphasis, includes documents naming the Teacher of Righteousness as a great authority. Within this group, some name the Teacher of Righteousness as a great authority. It is this group whose date is significant.

Of the 7 pieces tested by Jull et al. that are relevant to the Christian question, 3 are from documents directly naming the Teacher of Righteousness: 4Q171, 1QpHab, and 4Q266 (see below on the related $4 \mathrm{Q} 267$ ). The Teacher was a figure who appeared at a certain point of the Qumran history. The works naming him uphold his authority against an opponent or opponents, also called by pseudonyms, and the conflict between them is believed to be a matter of such magnitude that it is claimed to have been predicted in Old Testament scripture. 
There are only indirect indications of the date of the Teacher, and the interpretation of these has been a matter of debate.

The documents called $4 \mathrm{QpPs}^{\mathrm{a}}(4 \mathrm{Q} 171)$ and $1 \mathrm{QpHab}$ are examples of a genre of which a number of instances were found in the caves. Each is a pesher (plural, pesharim), that is, a commentary on a book of the Old Testament, claiming that its wording predicts events in the life of the Teacher and his opponents. Significantly, only one copy of each pesher was found in the caves, whereas multiple copies of other documents were found. The pesharim are an ephemeral genre of literature, referring to events in the author's own immediate circumstances, with the claim that they fulfilled prophecies. Once events changed, and the prophecies were seen to fit subsequent events better, the earlier document would be regarded as invalid. This would mean that no copies were made, each of the pesharim being an original.

(As the fact that there was only one edition of each of the pesharim is the foundation of this argument, a brief summary of the facts is given here. Eighteen fragmentary pesharim were found in the caves, 6 [3Q4, 4Q161, 4Q162, 4Q163, 4Q164, 4Q165] commenting on different sections of Isaiah; 2 [4Q166, 4Q167] on different sections of Hosea; 2 on different sections of Micah [1Q14, 4Q168]; 1 on Nahum [4Q169]; 1 on Habakkuk [1QpHab]; 2 on different sections of Zephaniah [1Q15, 4Q170]; 1 on Malachi [5Q10], 3 on different Psalms [4Q171, 1Q16, 4Q173]. Of the commentaries on Isaiah, all deal with different parts of the book, indicating that each pesher dealt with only a portion of it. In the one case where 2 different pesharim [4Q161, 4Q163] deal with the same 2 verses [Isa 10:20-22], it is plain that they are different compositions, for they break up the Isaiah verses differently when they add the pesher, and the pesher is different in each case).

\section{Q171 (4QpPsa)}

$4 \mathrm{Q} 171$ is a pesher on some Psalms. At the time it was composed, the Teacher of Righteousness was still alive, and under threat from his opponents. The pesharist, his supporter, turned to Psalm 37 and found there the teaching that even though the righteous person may suffer now, he will soon be vindicated and his enemies punished. He applied this, using his technique of turning universals into particulars, to the Teacher, who, he said, would soon be vindicated, while the opponents would be destroyed.

The principles of hypothetical document $\mathrm{C}$ apply to this work, the Teacher being person $\mathrm{X}$. He was still alive at the time it was recorded, and the document we have, being a pesher, is an original, not a copy. These exceptional circumstances mean that the earlier date of the ${ }^{14} \mathrm{C}$ range (Table 1 ) for the manufacture of the writing material gives us a probable date after which the Teacher was alive.

Both sets of ${ }^{14} \mathrm{C}$ ranges, that based on the 1986 curve, and that derived from the 1998 curve (Table 1), give a date in the 1 st century $\mathrm{CE}$ for this document: respectively, 22-78 CE and 29-81 CE. If it is the case that the ${ }^{14} \mathrm{C}$ dating is a reliable indicator (as further argued in the section "Doudna's Arguments"), this result gives good evidence that the document was composed and recorded after the twenties CE, and, since the Teacher was alive and active at the time of composition, he lived in the first Christian century, being contemporary with the early Christians. It would be clear evidence against the view held by the first generation of Scrolls scholars, that the Teacher lived in the second century BCE.

The handwriting of this piece is a Herodian semiformal (Cross 1961, note 134; Strugnell 1970, p 211), a fact that is omitted in the Tucson report. The handwriting of all the pesharim is Herodian, that is, a class of handwriting used from $30 \mathrm{BCE}$ to $70 \mathrm{CE}$. (Strugnell [1970] has treated 4QpIsac 
[4Q163], written on papyrus, as Hasmonean because it is in the same class as $1 Q S$, but see below on the paleography of $1 \mathrm{QS}$. He has also raised the possibility that the "vulgar semiformal" hand of $4 \mathrm{QpIsa}^{\mathrm{b}}$ (4Q162) is pre-Herodian, but such close distinctions in semiformals made by the early paleographers may now be doubted.)

This finding agrees with one possible interpretation of the indirect datings given for the Teacher in the Damascus Document (CD). They are not overt, and their interpretation has been disputed, but when the usages of the Scrolls are applied consistently, they may be seen to mean that the Teacher began his work in $26 \mathrm{CE}$ and died about $30 \mathrm{CE}$. The reasons in brief summary are as follows:

1. The wording of CD 1:5-11, concerning "the Period of Wrath, 390 years for his giving them into the hand of Nebuchadnezzar king of Babylon" is more correctly and consistently seen as a prediction of the length of the Roman occupation of Judea, the figure of 390 years being drawn from Ezekiel 4:5, treated as a prophecy in the habitual Qumran manner. In the pesharim it is asserted that "Babylon" of the Old Testament is an equivalent for Rome, a view found also in the New Testament, where "Babylon" is used as code for Rome (1 Pet 5:13, Rev 18). On this understanding, the ruler of Rome is being referred to by the writer of CD in a disguised way through a pseudonym, for political reasons. The usual translation of the phrase following " 390 years" is "after his giving them", but it should be "for his giving them", consistently with the normal meaning of the preposition. The Roman occupation of Judea, an event that could well be called "the Period of Wrath", took place in 6 CE (see further below). Since, according to the text, the Teacher came 20 years after the Period of Wrath, he began working in $26 \mathrm{CE}$.

2. The writer of CD 20:13-15 calculates that the death of the Teacher occurred about 40 years before a certain destruction of enemies. The destruction would result from a Visitation, an event expected in the near future. The Visitation is described in CD 19:10-16 using the language of the first fall of Jerusalem (Ezek 9:4). The passage may be understood as referring to another fall of Jerusalem, very shortly expected at the time of the writer. Jerusalem did fall in $70 \mathrm{CE}$; hence, on this interpretation, the Teacher died about 30 CE. (See Thiering 1979).

\section{QpHab: More Accurate $1 \sigma$ Range}

$1 \mathrm{QpHab}$, an extensively preserved pesher, is a commentary on the Old Testament book of Habakkuk, with frequent references to the Teacher and his rivals. He is spoken of as a past figure who had been defeated by his rivals, so it was composed after $4 \mathrm{QpPs}^{\mathrm{a}}$. Events in which he had been involved were vividly present to the writer, so, given the ephemeral nature of the pesharim, it would not have been composed too long after the events.

The first published ${ }^{14} \mathrm{C}$ date for this document was 104-43 BCE, based on the 1986 curve. But the 1998 curve gives a date of 88-2 BCE (Table 1).

The handwriting of $1 \mathrm{QpHab}$ is Herodian. It was copied by the same scribe as the second copy of the Temple Scroll, in a hand described as a developed Herodian formal from about 20-50 CE. (DJD 23, p 364).

Given these facts, and given the first century CE date of $4 \mathrm{QpPs}^{\mathrm{a}}$, which preceded this document, there is no great difficulty in supposing that a writer coming shortly after $4 \mathrm{QpPs}^{\mathrm{a}}$ recorded $1 \mathrm{QpHab}$ on a piece of writing material that was somewhat older than the writing material used by his colleague.

The question of the use of an older piece of material may be discussed in conjunction with the reaction of some Scrolls scholars to the Tucson date for this document, which they took to be definitive, and to be evidence against the Christian connection. In a footnote to their 'Atiqot publication of the 
results Jull et al. (1996) quoted a letter of 29 November 1992, from G. Vermes, a translator of the Scrolls, recommending that $1 \mathrm{QpHab}$ be tested: "If the carbon dating establishes (for $1 \mathrm{QpHab}$ ) a terminus ad quem prior to ca. $30 \mathrm{CE}$, this will damage almost beyond repair the hypothesis proposing a Christian connection".

But even in the absence of the subsequent calibration curves that render the date later, this was a historical non sequitur. Although a work could not be recorded on material that was not yet manufactured, it could well be recorded on material that had been manufactured many years before. Two pieces of evidence indicate that old materials were used at Qumran.

The first is a statement by Josephus that the Essenes (who formed the nucleus of the Qumran sectarians, even though ascetics of other outlooks joined them) "do not change their garments or shoes until they are torn to shreds or worn threadbare with age" (Jewish War 2, 126). This indicates that they had no objection to using old materials, and some may have found religious or ascetic reasons for doing so. Parchment remained usable for a long time, as is shown by the condition of pieces found in the caves after 2000 years. The parchment, "although hard and brittle when received, became relaxed and flexible on exposure to moisture" (DJD 1, p 39).

The other possible piece of evidence is the second sample in the Zurich list, the Testament of Qahat, $4 \mathrm{Q} 542$, whose $1 \sigma{ }^{14} \mathrm{C}$ date was given as 388-353 BCE or 309-234 BCE, but whose handwriting is paleographically dated to 100-75 BCE. (PAM 42.600, Eisenmann and Robinson 1991, plate 923; also PAM 43.565, Eisenmann and Robinson 1991, plate 1513). It uses letter forms found in the middle or late Hasmonean period, and it is certainly not an archaic script such as would match its ${ }^{14} \mathrm{C}$ dating. The authors of the Zurich report judged that "the possibility that the leather was preserved uninscribed for such a long period is quite unlikely" (although without taking into account the Essene habits), and suggested that contamination in this specific case could not be ruled out. Any contamination must have come from an even older source, since contamination by subsequently applied agents containing modern carbon gives a younger, not an older date than the true one. Pending further laboratory work, there is at least a possibility that a very old piece of material was used.

In this connection, Doudna's discussion of the ${ }^{14} \mathrm{C}$ dating of a linen wrapper that was probably found in Cave 4 is another example of not taking into account historical evidence for the use of old materials. He states that "the true date of the Cave 4 linen item is presumably close to the date when the scroll it was wrapped around was deposited in the cave", and goes on to suggest that this may be the date when all scrolls were deposited in Cave 4. The calibrated date range of the linen on the 1998 curve is $165-144 \mathrm{BCE}$ or 117-2 BCE, $1 \sigma$. (The $2 \sigma$ date of $197 \mathrm{BCE}-46 \mathrm{CE}$ is not quoted in the argument). However, it has frequently been suggested by Scrolls scholars that Cave 4 was a Genizah, a burial place for "dead" scrolls. Jewish tradition held that any document containing the name of God must not be destroyed, but buried, with a funeral service, as if it were human. It would be an expression of reverence to wrap the "body" in linen that had been preserved for a long time.

Moreover, the contents of $1 \mathrm{QpHab}$ may be seen as giving information about its date of composition. The situation of hypothetical document B applies to this work, which may be seen as describing events occurring in the first century CE. An army called the "Kittim" is described as a terrible and destructive force, marching across the land. It has long been accepted that the Kittim were the Romans, following Yadin's observations concerning the weaponry and military tactics of the Kittim, which were the same as distinctive practices of the Romans (Jeremias 1963). This is accepted by the most conservative of scholars, including Vermes (1995).

The Romans appeared in Judea as a terrible and destructive force only after 6 CE, when they occupied the country and put it under direct Roman rule. Prior to this, they had been distant overlords. 
Pompey had indeed, in $63 \mathrm{BCE}$, brought the country under Roman dominion, but he is not presented as a malevolent, overwhelmingly destructive power, as are the Kittim of 1QpHab. (The Kittim "march over the plain, destroying and plundering the cities of the earth.... The fear and dread of them is upon all the nations... in a council are all their plottings for evil, and with cunning and deceit they deal with all the peoples ... they trample the earth with their horses and beasts. From afar they come, from the islands of the sea, to devour all the peoples like an insatiable eagle.... They sacrifice to their standards and worship their weapons of war", 1QpHab 3:1-12, 6:3-4). Although Pompey entered the Holy of Holies, he treated it with respect, earning Josephus' praise for his "virtuous character" (Antiquities 14, 72-73). He restored a Jewish high priest to his place, and the country was thereafter governed by its own native high priests and kings. Only in $6 \mathrm{CE}$, after the dismissal of Archelaus Herod, did Judea become an occupied nation under the direct government of Roman procurators. The outrage at their presence was so strongly felt that a band of militants was formed, later called Zealots. They harassed the Romans until their activities brought about the destruction of Jerusalem later in the century.

Furthermore, there was a particular occasion in late $37 \mathrm{CE}$, recorded by Josephus, of a march of Roman soldiers across the land, when the army of the governor Vitellius passed through southern Judea, not far from Qumran. His action led to protest: "since he had started to lead his army through the land of Judea, the Jews of the highest standing went to meet him and entreated him not to march through their land. For, they said, it was contrary to their tradition to allow images, of which there were many attached to the military standards, to be brought upon their soil" (Antiquities 18, 120 122). Vitellius yielded to their request, having learned from the fate of the recently dismissed Pontius Pilate, who had been the most oppressive of the procurators up to that time. But the appearance of Vitellius' 2 legions of heavy-armed infantry and auxiliary light-armed infantry and cavalry would have evoked an initial reaction, bringing to the surface the anguish felt since the occupation. An involvement of the Qumran sectarians in zealotry may be argued from the contents of their document, the War Scroll, and from the fact that fragments of scrolls were found at Masada.

These circumstances may be understood as the background of $1 \mathrm{QpHab}$, which would have been composed toward the end of $37 \mathrm{CE}$, at the time of the initial reaction to the march of Vitellius. The writer not only expressed his fear of the Romans, but looked back to events in the life of the Teacher not many years before, finding them all "predicted" in the book of Habakkuk. This is consistent with a date for the death of the Teacher in about $30 \mathrm{CE}$.

\section{Doudna's Arguments Concerning 4QpPs a and 1QpHab}

While making valuable observations about the uncertainties of ${ }^{14} \mathrm{C}$ dating, Doudna's discussion of the two most significant documents for the Christian connection, 4QpPs $\mathrm{s}^{\mathrm{a}}$ and $1 \mathrm{QpHab}$, rests on unwarranted assumptions that are contrary to historical evidence or to the contents of the Scrolls. His main assumption, used not only in this case but in his treatment of other documents (4QTQahat and 4QLevia ar: Doudna 1998, p 445) is that if 2 documents, recorded by different scribes, are closely related in subject matter, then their writing materials must have been manufactured at similar dates. This is an unsustainable assumption, on general grounds. If two authors both discuss the same contemporary events, it does not prove that their writing paper was manufactured at the same time, or even in the same generation. Further, the evidence for the Essene use of old materials for religious reasons rules out this assumption altogether.

Doudna, agreeing that the subject matters and styles of the two key documents are closely related, and that there was only one copy of each of the pesharim, says, "There is thus good reason to expect that $4 \mathrm{QpPs}^{\mathrm{a}}$ and $1 \mathrm{QpHab}$ should be contemporaneous both in composition and in their single scribal 
copies. If this analysis is correct, the apparent difference in radiocarbon dates for $1 \mathrm{QpHab}$ and $4 \mathrm{QpPs}^{\mathrm{a}}$ may represent not a real difference in dates, but rather an anomaly in the radiocarbon measurements" (1998, p 453). Later he speaks of "the older radiocarbon date for 1QpHab, with which the scribal copy 4QpPsa ought to be contemporaneous" (p 461).

Choosing between the 2 dates, he concludes that $1 \mathrm{QpHab}$ is the preferable one. He holds that $4 \mathrm{QpPs}^{\mathrm{a}}$ may be an "outlier", a measurement that differs from that of other similar items without known cause, possibly through error. But his reason for this comes from a hypothesis that is not reconcilable with the contents: that all the Qumran Scrolls belong together in a single generation. He says that "since $4 \mathrm{QpPs}^{\mathrm{a}}$ has the youngest radiocarbon date for Qumran texts in either laboratory's group, its results are a priori of less secure confidence than the dates for the others" (p 461).

Few Scrolls scholars would agree that all the Scrolls belong together in a single generation. The foundation studies of such documents as the Community Rule and the Damascus Document, and of their relation to other documents, showed a process of development of the community organization over time. Further, the documents naming or reflecting the Teacher are a special group, which must be treated separately, as noted above. Some of the Scrolls show no knowledge of the Teacher and his distinctive doctrines and organization. It is the pesharim, together with the Damascus Document, the Community Rule probably, the Hymns of Thanksgiving, and other possible inclusions, that are relevant to the question of the Teacher. Within this group, all of the documents ${ }^{14} \mathrm{C}$-dated so far are capable of placing him in the first Christian century, as will be further shown below. Of the pesharim, only 2 of the 18 have so far been ${ }^{14} \mathrm{C}$-dated. It is erroneous to compare $4 \mathrm{QpPs}^{\mathrm{a}}$ with documents to which it is not related, and to say on this basis that it is an "outlier".

In comparing $1 \mathrm{QpHab}$ and $4 \mathrm{QpPs}^{\mathrm{a}}$ on the question of contamination, Doudna gives two reasons why the former was not contaminated. Of these, the first reason-that it was never in the Rockefeller Museum, where it is known that castor oil was used to make the letters clearer-is unpersuasive, for if the use of castor oil was a routine procedure, as stated, it may have been employed elsewhere. The second reason is more likely, that the tested piece was from a large amount of blank space, which would not have been subjected to castor oil. But this point applies also to $4 \mathrm{QpPs}^{\mathrm{a}}$, which has wide margins. Doudna, suggesting that $4 \mathrm{QpPs}^{\mathrm{a}}$ might have been contaminated, states that it was not subjected to acetone treatment, which would have removed castor oil, but he does not give any positive evidence that it was affected by castor oil. In fact, in his footnote 59 he allows that it is "intrinsically unlikely" that any given sample was so affected. (He does not mention that it was one of Tucson's "relatively clean" Type 1 parchment samples.)

It would appear that Doudna's final proposal, that "the first century CE disappears from Qumran's textual horizon" (1998, p 464) is not justified, either by his discussion of ${ }^{14} \mathrm{C}$ dating, concerning which he has mainly emphasized its uncertainty, or by ${ }^{14} \mathrm{C}$ dating taken in conjunction with paleography and the contents of the Scrolls.

\section{Q266: Evidence of a Particular Paleographical Error}

When the Zurich results were published, it was apparent that they were in good agreement with the paleographical datings already established for the 14 documents tested. This fact was seized upon by some Scrolls scholars as evidence against a Christian connection, for it was on the basis of paleographical findings that the Teacher had been placed in the 2nd or 1st centuries BCE, and it was believed that paleography had been vindicated.

But such a conclusion had not looked closely at the detail of the paleographical findings. In fact, only 2 published documents appeared to put the Teacher so early in terms of paleographic dating. 
They were 4Q266 and $1 \mathrm{QS}$, both now ${ }^{14} \mathrm{C}$ dated. 4Q266 is a copy of the work called the Damascus Document, which is not a pesher, but names the Teacher. 1QS, the Community Rule, reflects the Teacher's doctrine, although it does not name him.

On the rules of paleography alone, it was possible to demonstrate problems with the paleographical finding in both of these cases (Thiering 1979). As noted above, all the pesharim are in Herodian formal or semiformal scripts. If it were not for these two documents, 4Q266 and 1QS, the Teacher could have been placed in the Herodian period ( $30 \mathrm{BCE}-70 \mathrm{CE}$ ). But even one early document naming him, if it were certainly early, would be enough to place him before its time, in the Hasmonean period (150-30 BCE).

The script of 4Q266 had been announced to be early, and to place the Teacher somewhere before 60 BCE (Milik 1959, p 58). But the hand of this document is a semicursive, and the cursive and semicursive scripts are much more difficult to date than the formals and semiformals, as paleographers admit (Cross 1961, p 146, 182). They correspond to personal handwriting, whereas the formals were under controls like those of print, which are relied upon by paleographers. The writing of 4 Q266 is described in the official publication (DJD 18) as a "rapid and careless hand".

Doudna remarks that the ${ }^{14} \mathrm{C}$ dating of 4Q266 ( $1 \sigma 4-82 \mathrm{CE}, 2 \sigma 44 \mathrm{BCE}-129 \mathrm{CE}$ [Stuiver et al. 1998 values]) raises questions about the paleographical judgment. "It might be suggested that the highprecision paleographic estimates that have been given to these two texts (4Q266 and 4Q521) are somewhat premature" (1998, p 460). He leaves undetermined whether the radiocarbon evidence should be allowed to correct the paleographical conclusion. It may be argued however, that the discrepancy comes from giving too firm a date to a semicursive, a notoriously slippery class for paleographers.

If the ${ }^{14} \mathrm{C}$ dating is a reliable indicator, the $1 \sigma$ range, $4-82 \mathrm{CE}$, allows the inference from this document, taken alone, that the Teacher lived in the 1st century CE. However, the Damascus Document was found in multiple copies, and further factors must be taken into account in determining its date of composition. The ${ }^{14} \mathrm{C}$ result for $4 \mathrm{Q} 267$ is relevant to it; see below.

\section{Q267: An Early Source of the Damascus Document}

Also tested (Tucson) was 4Q267, a more recently published fragment of the Damascus Document. The nature of the Damascus Document is relevant to the consideration of this piece and 4Q266.

The complete version of this work is known to us from medieval copies that were found in Cairo and published in 1910. Many fragments of it were subsequently found in the Qumran caves, and it could be seen that it had originally come from a stage when Qumran sectarians were in Damascus. Although most of it is concerned with laws, parts of it deal with the history of the Teacher of Righteousness and his rivals, treating them in much the same way as does $1 \mathrm{QpHab}$. It appears that the rivals, who had become powerful in Judea, had been the cause of the sectarians' exile to Damascus.

Whereas the fragments of $4 \mathrm{Q} 266$ represent a fairly extensive version of the Damascus Document, running parallel to the medieval copy, 4Q267 consists of only a small group of fragments. They are in an early Herodian formal hand (DJD 18, p 96). None of the extant parts of the fragments contain references to the history of the Teacher of Righteousness and his rivals. (A reconstruction of fragment 2, line 15, may give the phrase "law-interpreter", but according to 1QS 6:6 this means a levite subordinate to a priest, whereas the Teacher was a priest. A reconstruction of fragment 3 , line 7 , may perhaps speak of "a teacher", but not of the Teacher of Righteousness. In both cases, the full version of the text, CD itself, goes on to speak of the Teacher of Righteousness, but if our argument that 
4 Q267 is a source is correct, it will have been the case that the full version added these references to the source.)

Fragment 2 of 4Q267, although not referring to the Teacher, is relevant to the question, as it corresponds to CD 5:17b-6:7. In the full CD, 5:17b-6:7 is a new section immediately following an account of the Teacher and his disputes. This section, placed in column 5, differs from what precedes, in that it introduces the word "Damascus" for the first time, in the context of the exile of the men of the community.

The 1998 calibration gives to 4 Q267 a $1 \sigma$ date of $168-51$ BCE, $2 \sigma 198-3$ BCE. Following the argument above, that 4Q266 was recorded in the 1st century CE, with the implication that it may have been composed then, it would not be impossible to argue that 4Q267 was simply the remains of another copy of the work on an older piece of material.

However, a secondary question arises concerning CD itself, one that would make the argument for an old piece of material unnecessary. A close study raises the probability that $4 \mathrm{Q} 267$ is a source, composed in the first century BCE, which was subsequently incorporated into $\mathrm{CD}$, a document that is known to have been composite. The stages will have been:

1. 4Q267, dealing with an exile to Damascus in the 1st century BCE, and justifying it as directed by God.

2. 4Q266, dealing with a subsequent exile to Damascus (a natural place for political exiles, just outside the boundaries of Judea) in the 1st century CE, the document now beginning with the recent history of the Teacher and his rivals. It incorporated parts of 4Q267, placing the Damascus passage in its column 5, after its treatment of the Teacher. The inclusion was in order to endorse the argument concerning Damascus.

3. The final version, which was copied in medieval times.

The argument for this is as follows:

A. The wording of fragment 1 of $4 \mathrm{Q} 267$ corresponds, as is recognized, to the wording of another fragment of $\mathrm{CD}$. This latter piece was found still attached to its fastening, proving that the words in question were part of an opening column. The piece attached to the fastening is in a semicursive script, whereas 4Q267 is in a formal script. But 4Q266 is in a semicursive script, and for that reason the piece attached to the fastening was placed with 4Q266, as its opening column.

But close study shows that it was an error to put the two semicursive pieces together. They are in a different semicursive hand. Although the fragment attached to the fastening was small, the following differences in the method of drawing the letters may be observed, showing a recurring characteristic, that the scribe of 4Q266 makes fuller strokes than does the other scribe:

\begin{tabular}{lll}
\hline Letter & 4Q266 & Fragment attached to fastening \\
\hline Lamedh & full hook & short hook \\
Ayin & full right arm & short right arm \\
Mem & base and oblique nearly joined & space between base and oblique \\
Taw & full left stroke & short left stroke \\
Beth & long base & more even top and base \\
Shin & long center and right strokes & short center and right strokes \\
Qof & flat top, angle at right corner & more rounded top \\
Tet & slanted base & straight base \\
\hline
\end{tabular}


B. The wording of the piece attached to the fastening (which on this argument remains without a siglum), and of its parallel 4Q267 fragment 1, give further reasons for believing that they represent a document that was different from the full version of CD: 1) if the reading "sons of light" in line 1 of the attached fragment is correct, then the piece does not belong to the longer $\mathrm{CD}$, where this significant term — often used as a basis for analysis—is not found. 2) The attached fragment uses the first person plural for the author in line 19. The first person plural is not used in the longer CD (except in an acknowledged quotation, 20:29).

C. These observations raise the probability that $4 \mathrm{Q} 267$ and the fragment attached to the fastening represent two different copies, in different handwriting, of the same document, a document that was not the same as the fuller CD. Parts of it were incorporated in the fuller CD, but not its opening column. Since the extant fragments of $4 \mathrm{Q} 267$ do not deal with the Teacher, it may reasonably be supposed that the document was a source preceding the time of the Teacher. Its early ${ }^{14} \mathrm{C}$ dating, then, is not evidence for the early date of the Teacher.

Thus the inference from the ${ }^{14} \mathrm{C}$ dating of $4 \mathrm{Q} 266$, that the Teacher lived in the 1 st century $\mathrm{CE}$ (see previous section) is unaffected by the ${ }^{14} \mathrm{C}$ dating of $4 \mathrm{Q} 267$.

\section{QS and 4Q258: The Community Rule}

$1 \mathrm{QS}$ and 4Q258 are 2 copies of the same work, the Community Rule or Manual of Discipline. Its principal version is known to us in 11 complete columns, called $1 \mathrm{QS}$ because it was found in Cave 1. The other, 4Q258, found in Cave 4, is a fragment, corresponding to 1QS 5:1 ff, in a different hand from 1QS. The work is in the form of regulations governing the life of the community, which was bound to obedience. Parts of it may be understood as containing doctrine and legislation like that of the Teacher, although he is not named.

Because of characteristics of the 1998 calibration curve and the large error associated with the ${ }^{14} \mathrm{C}$ measurement, the full document 1QS yielded two $1 \sigma$ ranges, 164-144 BCE and $116 \mathrm{BCE}-50 \mathrm{CE}$, spanning a wide age range (Stuiver et al. 1998 values, Table 1).

The hand of 1QS is not a normal one, but an unusual, highly embellished one, said from the first to be atypical, and presenting a complicated problem (Cross 1961, note 116). Cross put it in the class of Hasmonean semiformal, making it early first century BCE, but it can be shown that it combines Herodian forms with letter forms used in the related Palmyrene scripts (Thiering 1979). Palmyrene scripts using the same forms are actually dated in the early Herodian period, and the forms continued to be used well into the Christian period.

The related sample, $4 \mathrm{Q} 258$, had to be tested twice because of possible contamination, but the second test yielded a $1 \sigma$ calibrated age within the Christian period, 36 BCE-81 CE (Stuiver et al. 1998 values, Table 1). Its hand has been described by Cross (1994) as "early Herodian formal". (This corrects the statement on its paleography in Jull et al 1995, p 18.)

These facts are consistent with a view that the Community Rule was compiled during the first centuries BCE and CE as a legal document by which members of the Qumran community were bound. It is known to reflect different stages of organization. The argument would be that its final form, 1QS, incorporating the Teacher's doctrine, was recorded in the 1st century CE in an embellished, unusual hand, to give it prestige, as legal documents still are. The ${ }^{14} \mathrm{C} 1 \sigma$ range of $116 \mathrm{BCE}-50 \mathrm{CE}$ (Table 1) would permit a first century CE date of manufacture of the material (but see further below on $4 \mathrm{QSam}{ }^{c}$ ). 4Q258, corresponding to part of it, would be a source that appeared during the process of compilation. 
Any discussion of 1QS must take into account a document tested by the Zurich laboratory, 4QSam ${ }^{\mathrm{c}}$, which was written by the same scribe as 1QS (Cross 1961, note 116). The hand, as shown above, is an idiosyncratic one, combining late Palmyrene with Herodian features. The ${ }^{14} \mathrm{C} 1 \sigma$ range of 4QSamc is 196-47 BCE (Doudna 1998, Table A). Since a first century CE date for the final form of 1QS may be argued, as shown above, it would follow that the scribe of both works chose to use for $4 Q \mathrm{Sam}^{\mathrm{c}}$ a piece of some antiquity, consistently with Essene habits. This may also have been the case with the piece he chose to record $1 \mathrm{QS}$, whose ${ }^{14} \mathrm{C}$ dating presents a very broad range. Given the embellished nature of the handwriting, and the authority of the subject matter in both cases, it is feasible that venerable pieces of parchment were used by this scribe.

\section{Q521}

Another document in the Tucson group, 4Q521, called The Messianic Apocalypse, has been given a dating that could help to challenge a view that it was a very early composition. This work contains doctrinal parallels to the New Testament. It has aroused considerable interest for that reason, but it is less relevant to the historical question, as it does not deal with history or mention the Teacher. However, its placement in the late first century BCE or first century CE ( $1 \sigma$ calibrated age 39 BCE66 CE, Stuiver et al. 1998 value, Table 1) gives chronological plausibility to an argument for a historical connection between Qumran and the early Christians.

Its hand has been defined as Hasmonean formal (DJD 25, p 3). Making the usual allowance for "the extension of the professional life of a conservative scribe beyond his generation, or for an individualistic hand" (Cross 1961, note 29), it could have been used in the early Herodian period, indicating that its doctrinal concerns preceded the similar ones of Christians. In his official publication of the document (DJD 25, 1998) Puech refers to the ${ }^{14} \mathrm{C}$ dating but cites only the broad $2 \sigma$ range, $93 \mathrm{BCE}-$ $80 \mathrm{CE}$ (Tucson, using the 1986 calibration curve).

\section{The Two Zurich Documents Relevant to the History}

The conclusion that the Zurich results gave evidence against the Christian connection came not only from inadequate observation of the paleographical detail, as shown above, but also from inadequate observation of the contents of the documents tested. Only two of them were relevant to the history. One was the Temple Scroll (11Q19, 11QTa), which clearly came from a first stage of the sectarian development, preceding but related to subsequent works such as the War Scroll and the Community Rule. The other was the Hymns of Thanksgiving (1QH), which was established by Jeremias (1963), on the basis of word frequencies and common terms, to have been partly composed by the Teacher of Righteousness.

It had been argued (Thiering 1979), from the contents of the documents alone, that the Temple Scroll was composed about $21 \mathrm{BCE}$, at the time Herod the Great announced his plan for rebuilding the temple. The Qumran sectarians, encouraged by Herod's approval of the Essenes at that time (as recorded by Josephus) were offering their plan for the new temple, claiming that it had been divinely revealed. This interpretation is entirely compatible with both the original Zurich dating (97 BCE-1 CE) and with the more recent calibration, 53 BCE-21 CE (Table 1). It is also compatible with the scroll's Herodian hand.

The Thanksgiving Scroll's calibrated age of 21 BCE-61 CE, given by Zurich, and 37 BCE-68 CE from the 1998 calibration, is also consistent with parts of it having been composed by the Teacher of Righteousness between 26 and about $30 \mathrm{CE}$. 


\section{CONCLUSION}

The radiocarbon dating of the relevant group of sectarian documents within the Dead Sea Scrolls, when correlated with paleography and the contents of the documents, allow the possibility that the Teacher of Righteousness lived and died during the period of the foundation of Christianity. This conclusion is contrary to a view now commonly held, that the radiocarbon datings have disproved a Christian connection.

\section{ACKNOWLEDGMENT}

We thank Drs A J T Jull and T Higham for their helpful assistance.

\section{REFERENCES}

[DJD 1] Barthelemy D, Milik JT. 1955. Qumran Cave I. Discoveries in the Judaean Desert 1. Oxford: Clarendon Press. 165 p.

[DJD 18] Baumgarten JM. 1996 Qumran Cave 4, XIII: The Damascus Document (4Q266-273). Discoveries in the Judaean Desert 18. Oxford, Clarendon Press. $236 \mathrm{p}$.

[DJD 23] by Garcia Martinez F, Tigchelaar EJC, van der Woude AS. 1998. Qumran Cave 11, II: 11Q2-18, 11Q20-31. Discoveries in the Judaean Desert 23. Oxford, Clarendon Press. 487 p.

[DJD 25] Puech E. 1998. Qumran Grotte 4, XVIII: Textes hébreux (4Q521-4Q528, 4Q576-4Q579). Discoveries in the Judaean Desert 25. Oxford, Clarendon Press. $229 \mathrm{p}$.

Bonani G, Broshi M, Carmi I, Ivy S, Strugnell J, Wolfi, W. 1991. Radiocarbon dating of the Dead Sea Scrolls. 'Atiqot 20:27-32.

Bonani G, Ivy S, Wolfi W, Broshi M, Carmi I, Strugnell J. 1992. Radiocarbon dating of fourteen Dead Sea Scrolls. Radiocarbon 34(3):843-9.

Caldararo N. 1995. Storage conditions and physical treatments relating to the dating of the Dead Sea Scrolls. Radiocarbon 37(1):21-32.

Cross, FM. 1961. The Development of the Jewish scripts. In: Wright GE, editor. The Bible and the ancient Near East. London: Routledge \& Kegan Paul. p 133-202.

Cross, FM. 1994. Paleographical dates of the manuscripts. In: Charlesworth JH, editor. The Dead Sea Scrolls, Hebrew, Aramaic and Greek texts with English translations. Volume 1. Tubingen: J. C. B. Mohr. p 57.

Doudna G. 1998. Dating the Scrolls on the basis of radiocarbon analysis. In: Flint PW, Vanderkam JC, editors. The Dead Sea Scrolls after fifty years. Volume 1. Leiden: Brill. p 430-71.

Eisenmann RH, Robinson JM, editors. 1991. A facsimile edition of the Dead Sea Scrolls. Washington DC: Biblical Archaeology Society.

Garcia Martinez F. 1994. The Dead Sea Scrolls translated: the Qumran texts in English. Leiden, Brill. 513 p.

Jeremias G. 1963. Der Lehrer der Gerechtigkeit. Göttingen, Vandenhoeck \& Ruprecht. 376 p.

Jull AJT, Donahue DJ, Broshi M, Tov E. 1995. Radiocarbon dating of scrolls and linen fragments from the Judean desert. Radiocarbon 37(1):11-19.

Jull AJT, Donahue DJ, Broshi M, Tov E. 1996 Radiocarbon dating of scrolls and linen fragments from the Judean desert. 'Atiqot 28:85-91.

Milik JT. 1959. Ten years of discovery in the wilderness of Judaea London: SCM. 160 p.

Rodley GA. 1993. An assessment of the radiocarbon dating of the Dead Sea Scrolls. Radiocarbon 35(2):3358

Strugnell J. 1970. Notes en marge du volume V des "Discoveries in the Judaean Desert of Jordan". Revue de Qumran 7(26): 163-76.

Stuiver M, Becker B. 1986. High-precision decadal calibration of the radiocarbon time scale, AD 1950-2500 BC. Radiocarbon 28(2B):863-910.

Stuiver M, Pearson GW. 1986. High-precision calibration of the radiocarbon time scale, AD 1950-500 BC. Radiocarbon 28(2B):805-38.

Stuiver M, Reimer PJ, Bard E, Beck JW, Burr GS, Hughen KA, Kromer B, McCormac G, van der Plicht J, Spurk M. 1998. INTCAL98 radiocarbon age calibration, 24,000-0 cal BP. Radiocarbon 40(3):10411083.

Thiering BE. 1979. Redating the Teacher of Righteousness. Sydney: Theological Explorations. 234 p.

Vermes G. 1995. The Dead Sea Scrolls in English. Rev and ext 4th ed. London: Penguin Books. 392 p. 